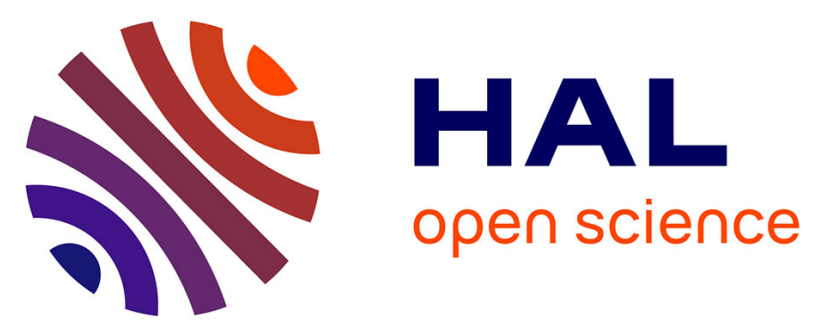

\title{
SmartLoire: A Web Mashup Based Tool for Personalized Touristic Plans Construction
}

Marwa Boulakbech, Nizar Messai, Yacine Sam, Thomas Devogele, Laurent Etienne

\section{- To cite this version:}

Marwa Boulakbech, Nizar Messai, Yacine Sam, Thomas Devogele, Laurent Etienne. SmartLoire: A Web Mashup Based Tool for Personalized Touristic Plans Construction. 2016 IEEE 25th International Conference on Enabling Technologies: Infrastructure for Collaborative Enterprises (WETICE), Jun 2016, Paris, France. pp.259 - 260, 10.1109/WETICE.2016.66 . hal-01512953

\section{HAL Id: hal-01512953 https://hal.science/hal-01512953}

Submitted on 24 Apr 2017

HAL is a multi-disciplinary open access archive for the deposit and dissemination of scientific research documents, whether they are published or not. The documents may come from teaching and research institutions in France or abroad, or from public or private research centers.
L'archive ouverte pluridisciplinaire HAL, est destinée au dépôt et à la diffusion de documents scientifiques de niveau recherche, publiés ou non, émanant des établissements d'enseignement et de recherche français ou étrangers, des laboratoires publics ou privés. 


\title{
SmartLoire: A Web Mashup Based Tool For Personalized Touristic Plans Construction
}

\author{
Marwa Boulakbech, Nizar Messai, Yacine Sam, Thomas Devogele and Laurent Etienne \\ Franois Rabelais Tours University, Tours, France \\ Email: firstname.lastname@univ-tours.fr
}

\begin{abstract}
A large set of Web services are nowadays available providing complementary content about: schedule of public transportation, description of touristic area, meteorological information, geocoding operations, etc. We present in this article a mobile-application prototype that mashups Web services to define custom touristic plans, i.e., takes into account tourist preferences (type of stay, interest) and constraints (duration, budget, locomotion modality). Moreover, the application considers real-time events (e.g., weather data or temporary unavailability of a touristic site) to adapt proposed schedules.
\end{abstract}

Keywords: Web mashup, geospatial Web services, e-tourism, itinerary construction, preference, constraint.

\section{INTRODUCTION AND PROBLEM}

The region Centre Val de Loire, in the center of France, is characterized by its huge and diversified touritic heritage, It counts a large number of castles, gardens, tourism offices, wine cellars, wonderful places, etc. This diversity is also present at the level of Internet, where the touristic products and services are described in a large number of Web sites. These sites are often heterogeneous since each of them presents its information (touristic program, opening hours, prices, etc.) in its own data formats and focuses on specific points of interest. More recently, the trend is in offering touristic information via mobile applications (m-tourism), that allows taking benefit from geolocation option in order to help tourists to find and join their touristic points of interest. They generally consist in the proposition of pre-established touristic plans composed as lists of touristic points of interest ordered by closenesses to the tourist position. The tourist has sometimes the possibility to define a unique search criterion such as "family travels" or "vineyards" (http://www.coeur-val-de-loire.com/). Some of them are more specific, such as "Pirates de Loire" (http://piratesdeloire.com/) which is intended for the children. But, generally, the existing Web-sites/mobile-applications lack personalization, the tourists wishing to organize a personalized stay to discover the region has to make a greet effort (browsing several web-sites, problem of inconsistent and redundant information, local events like meteorology and congestion of touristic points of interest are not taken into consideration, etc.) to construct an adequate touristic plan, i.e., that satisfy her constraints and preferences.

\section{General ARCHItECTURE}

We propose SmartLoire, a platform allowing to guide the tourist in the construction of her touristic plan according to her constraints and preferences expressed through a mobile device. Among the numerous preferences which can be taken into consideration: the type of the place to visit (castles, gardens, wine cellars, landscapes, cities, etc.), the density (allows to define if the tourist wishes to visit a maximum of places or to take her time), inescapable or unusual places, etc. The constraints can be the duration of the stay, the maximum budget, the type of the visit (solo, family, couple, group, elderly people, persons with reduced mobility, etc.), the type of accommodation, the type of restoration, the transportation mode, etc. Our approach can be seen as smart city [1] like vision of e-tourism [2]. It is based on Service Oriented Computing paradigm and Web services technology [3] allowing interoperability, between heterogeneous touristic points of interest (type, adress, opening hours, etc), and services composition thanks to Web standards.

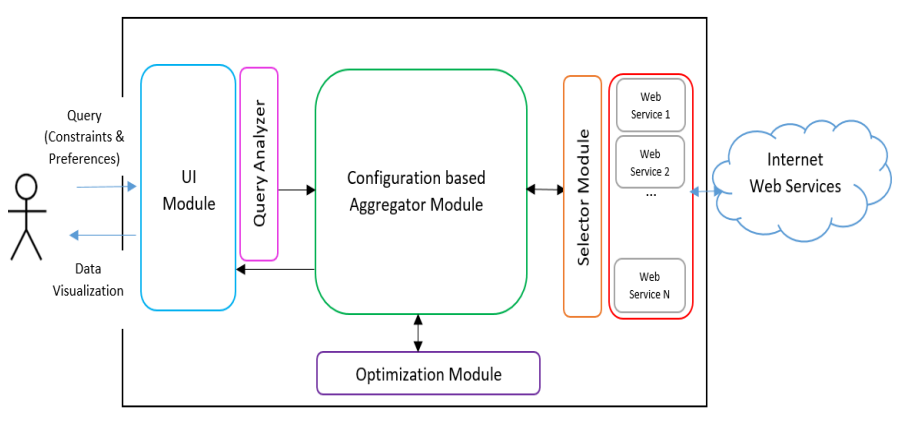

Fig. 1. Application architecture.

SmartLoire aggregates content (data services, data integration and processing operators, visualization tools, etc.) providing from different Web services to construct a Web mashup (http://www.programmableweb.com/, [4]). Besides general services such as weather services, maps visualization services and cloud services allowing to host specific applications, some touristic information suppliers (transportation, accommodations, museums, etc.) offer their public APIs allowing to partially reuse their data and/or applications.

The architecture of the application is depicted in Figure 1. The aggregation process is based on configuration, a well established theory in Artificial Intelligence allowing to compose complex objects [5]. Many approaches exist in the literature that tackles the problem of RESTful Web services composition using different techniques (for example [6], [7] or [8]), we propose here to use configuration to aggregate 
data and services in the presence of user preferences and constraints.

\section{SMARTLOIRE PROTOTYPE}

The first prototype of our approach was implemented. Based on a collection of services: Weather API Web Service (http: //openweathermap.org/api - meteo service), Mapquest Open Geocoding Service(http://developer.mapquest.com/ - transform adress on (latitude, longitude) and vice versa), Mapquest Open Directions Service (http://developer.mapquest.com/ getting routing information between two positions), Google Places API Web Service(https://developers.google.com/places/ webservice/ - returns information on geographical points such as hotels, restaurants and others, etc.), SNCF Open Data API (https://data.sncf.com/ - transportation information), OpenStreetMap (http://wiki.openstreetmap.org/wiki/API_v0.6 - a collaborative map free service), etc., we were able to define a new Web service, SmartLoire, available also as an Android mobile application, allowing touristic plans construction. We have used OpenShift (https://www.openshift.com/ platform for services development and deployment allowing programmers to quickly develop large-scale applications in a cloud computing style environment). This solution was preferred to other platforms such as Cloud Foundry (http:// cloudfoundry.org/) in particular, because it allows an automatic scalability of the application. This property is very useful for the automatic management of http requests. This new service is developed for Android smartphones by means of the Android SDK (https://developer.android.com/sdk/index.html) and ADT (http://developer.android.com/tools/help/adt.html). The application is written in Java.

From a tourist point of view, using our tool is simple. First, she defines her preferences and constraints. In the version 1, the interface allows to mention the budget, the desired mean of transportation and the duration of the visit (Figure 2, (left)). This data will be taken into account by the application during the definition of the touristic plan.
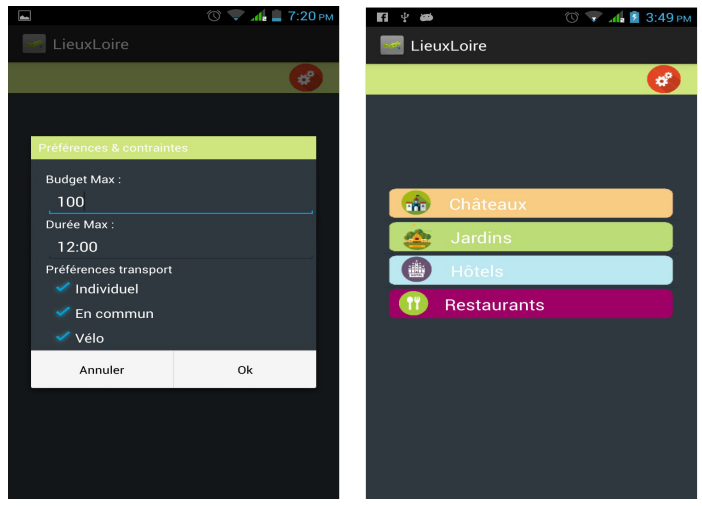

Fig. 2. Preferences/constraints UI (1) and Centers of interests categorized (r).

The user selects then her centers of interest in a set of categories (castles, gardens, hotels and restaurants - Figure 2 , (right)). To improve our application, it will be necessary to add new categories in future versions.

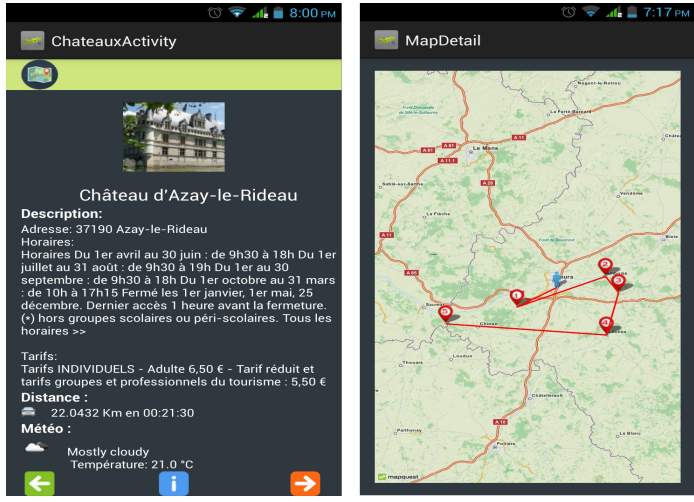

Fig. 3. Center of interest detail (1) and touristic plan (r).

After this step, the tourist will interactively choose the categories and places interested in and can selects the means of transportation to be used. More information about each selected place can be given (opening hours, weather, etc.) (Figure 3, (left)). We notice here that only information satisfying the preferences and constraints of the user are displayed during the plan construction process thanks to the implemented algorithm. The whole touristic plan is finally displayed on a map (Figure 3, (right)).

\section{PERSPECTIVES}

This first version of SmartLoire is a prototype allowing to demonstrate the validity of Web mashup idea for personalized tourists plan construction. This prototype can be improved and the features to consider in the future versions of the application are : $(i)$ covering the three big stages of a tourist stay (before, during (for dynamic plans generations) and after (for trajectories analysis [9])); (ii) touristic plans optimization ; (iii) multimodal transportation (soft, collective, automobile) ; (iv) real-time monitoring of tourists in order to update tourists preferences using her real choices.

\section{REFERENCES}

[1] H. Schaffers et al. Smart Cities and the Future Internet: Towards Cooperation Frameworks for Open Innovation. Future Internet Assembly, 6656, 431-446, 2011.

[2] D. Buhalis and R. Law, Progress in information technology and tourism management: 20 years on and 10 years after the InternetThe state of eTourism research, Tourism management, 29(4), 609-623, 2008.

[3] G. Alonso and F. Casati, Web Services and Service-Oriented Architectures. ICDE 2005, 1147.

[4] J. Yu, B. Benatallah, F. Casati and F. Daniel, Understanding Mashup Development, IEEE Internet Computing 12(5): 44-52 (2008).

[5] B. Stein, Functional models in configuration systems., Universitt Paderborn 1995, pp. I-XI, 1-145.

[6] F. Daniel and M. Matera, Mashups: Concepts, Models and Architectures., Springer, Heidelberg (2014)

[7] M. Gebremariam et al., Towards end-user development of REST client applications on smartphones., Computer Standards Interfaces 44 (2016): 205-219.

[8] G. Ghiani et al., An environment for End-User Development of Web mashups., International Journal of Human-Computer Studies, 87, 2016.

[9] L. Etienne, Motifs spatio-temporels de trajectoires d'objets mobiles, de l'extraction la détection de comportements inhabituels. Phd Thesis, Institut de Recherche de l'Ecole Navale, 2011. 